\title{
TRANSITIVITAS DALAM BAHASA INDONESIA DAN BAHASA SUNDA
} Transitivity in Indonesian and Sundanese Language

\section{Puspa Mirani Kadir, Pika Yestia Ginanjar, dan Cece Sobarna}

Universitas Padjadjaran

Jl. Raya Bandung Sumedang KM.21, Kabupaten Sumedang, Jawa Barat, Indonesia puspa.mirani@unpad.ac.id

Naskah Diterima Tanggal 1 Juni 2021—Direvisi Akhir Tanggal 19 September 2021-Disetujui Tanggal 23 Desember 2021 doi: https://doi.org/10.26499/rnh/v10i2.4148

\begin{abstract}
Abstrak
Fenomena kebahasaan banyak ditemukan dalam bahasa Indonesia dan bahasa Sunda, salah satunya adalah bahasan verba pasif, terutama pada saat verba tersebut mengalami pembentukan kata turunan baik melalui proses afiksasi, reduplikasi maupun pemajemukan. Hopper dan Thompson (1980) menjelaskan hubungan transitivitas dan diatesis pada struktur gramatikal verba, khususnya pada bidang kajian affectedness of object yang mengklasifikasikan ketransitifan ke dalam dua jenis: (1) ketransitifan struktural yang berhubungan dengan predikat dan dua buah argumen inti; (2) Ketransitifan tradisional yang berhubungan dengan semua unsur di dalam sebuah klausa pemindahan tindakan dari agen ke pasien (Hopper \& Thompson, 1980). Tujuan penelitian ini adalah mendeskripsikan tingkat transitivitas bahasa Indonesia dengan melakukan penelitian kontrastif dengan bahasa Sunda, berdasarkan teori Hopper dan Thompson (1980) yang memfokuskan kajian pada konstruksi tengah. Data bahasa Sunda diambil dari contoh kalimat yang ada dalam Majalah Mangle (Edisi 2018-2019), naskah drama "Lalakon”, dan buku "Kajian Bentuk dan Makna Konseptual Preposisi Bahasa Sunda” (Sobarna, C. dan Santy, 2019). Hasil pembahasan konstruksi tengah (middle construction), terlihat bahwa adanya keterkaitan erat antara struktur kalimat pasif bahasa Sunda yang berprefiks $\boldsymbol{k a}$-,ti-, berinfiks -ar- dan struktur kalimat bahasa Indonesia yang memiliki verba berprefiks ter-., serta verba bahasa Indonesia tidak terlepas pada perbuatan/aktivitas pelaku apakah itu disadari atau tidak disadari.
\end{abstract}

Kata-kata Kunci: derajat ketransitifan, verba transitif, verba intransitif, transitivitas, middle contruction

\begin{abstract}
The phenomenon of language is found mainly in Indonesian language and Sundanese language, one of which is the passive verbs; especially when the verb experiences the process of forming derivative words, either through affixation, reduplication, and compounding. Hopper and Thomson (1980) explain the relationship of transitivity and diathesis in the grammatical structure of verbs, especially in the field of study of affectedness of object; transitivity is divided into two types; (1) structural transitivity related to the predicate and two main arguments; and (2) traditional transitivity related to all elements in a clause transferring the action from agent to patient. This research aims to describe the transitivity level of Indonesian language by doing contrastive research with Sundanese language, based in the theory of Hopper and Thompson (1980) which focuses on the middle construction. The Sundanese language data is taken from sample sentences in Mangle Magazine (Edition 20182019), the drama script "Lalakon", and book "Kajian Bentuk dan Makna Konseptual Preposisi Bahasa Sunda"(Sobarna, C. dan Santy, 2019). The research results show there is a close relationship between Sundanese language passive sentence structures with prefixes $\mathrm{ka-}$ - $\mathrm{ti}$-, with the infix -ar-and Indonesian language sentence structures with verbs prefixed ter-, also and Indonesian language verbs cannot be separated from the actions/activities of the actors, whether it is realized or not.
\end{abstract}

Keywords: degree of transitivity, transitive verb, intransitive verb, transitivity, middle construction

How to Cite: Kadir, Puspa Mirani. dkk. (2021). Transitivitas dalam Bahasa Indonesia dan Bahasa Sunda. Ranah: Jurnal Kajian Bahasa. 10(2). 443-451. doi: https://doi.org/10.26499/rnh/v10i2.4148 


\section{PENDAHULUAN}

Ketransitifan dipandang bukan sekadar menyangkut ihwal jumlah frasa nomina yang menyertai verba, melainkan berkenaan dengan hubungan yang diturunkan dari wacana yang lebih kuat proporsinya terhadap intensitas kejadian yang diungkapkan oleh klausa itu. Intensitas kejadian yang dimaksudkan dengan intensitas adalah derajat ketransitifan -diukur sebagai kumpulan sejumlah parameter, dan setiap parameter itu menyumbangkan sesuatu pada hubungan ketransitifan.

Parameter tersebut merupakan ciri prototipe transitivitas yang dapat membantu dan menganalisis verba bahasa Indonesia dan bahasa Sunda, yang dapat diamati pada; Peserta (Participants), Kinesis; Aspek (Aspect), Kepungtualan (Punctuality), Kesengajaan (Volitionality), Kekutuban (Affirmation), Modalitas (Mode), Daya agen (Agency), Keterkenaan pasien (Affectedness of $O$ ) dan Individuasi pasien (Individuation of $O$ ) (Hopper \& Thompson, 1980). Derajat transitivitas tidak ditentukan seccara mutlak harus memiliki semua ciri prototipe tersebut, namun yang terpenting adanya perlakuan pada salah satu ciri tersebut.

Pada contoh kalimat "Salju mencair", menunjukkan bahwa kalimat ini memiliki kedudukan yang rendah dalam tingkatan transivitasnya. Dengan parameter ketransitifan ini, dapat mengungkap ketransitifan verba bahasa Indonesia dan melihat padanan pada bahasa Sunda.

Ketransitivitasan setiap bahasa akan berbeda sesuai dengan ciri bahasa tersebut, (Paulino et al., 2019) mengungkapkan derajat ketrasitifan verba dialek Ritaebang memiliki ketransitifan tinggi berdasarkan parameter Hopper dan Thompson (1980). Bahasa daerah di Indonesia sangat beragam, hal ini yang menjadi alasan kuat penulis memilih Bahasa Sunda untuk dikomparasikan dengan Bahasa Indonesia. Pada penelitian ini pemilihan bahasa Sunda bukan hanya karena merupakan bahasa ibu, namun juga dalam bahasa Sunda terdapat beberapa variasi dalam verba pasif dengan imbuhannya.

Penelitian komparatif verba pasif, transitif-intransitif sebelumnya pernah penulis lakukan dengan membandingkan antara bahasa Jepang dan bahasa Indonesia, yang dijadikan buku referensi (Kadir dan Ginanjar, 2018). Hal ini pula yang menjadi acuan penulis untuk mencoba membandingkan antara bahasa Indonesia dengan bahasa Sunda.

Verba pasif dalam bahasa Sunda yang menguasai kepemunculan preposisi dapat berprefiks $\boldsymbol{d i}$ - dengan variasinya, serta umumnya verba pasif berprefiks $\boldsymbol{d i}$ - ini menguasai preposisi agentif $k u$, dengan pola Verba pasif \pm preposisi di, dina, $k \boldsymbol{a}$, $\boldsymbol{k a n a}$, $\boldsymbol{t} \boldsymbol{i}$ sebagai pewatas (Sobarna, C. dan Santy, 2019), sehingga memiliki derajat lebih tinggi

Penelitian ini bertujuan dapat mengungkap ketransitifan verba bahasa Indonesia dengan melihat padanan pada bahasa Sunda, berdasarkan derajat ketransivitasannya, hal ini sejalan dengan penelitian terdahulu (Darheni, 2010), akan tetapi pada penelitian ini fokus pembahasan bukan hanya melihat rendah atau tinggi nya parameter, namun perlu adanya pembahasan middle construction, yang merupakan ciri khas struktur kalimat middle berdasarkan skala transitivitas (Hopper \& Thompson, 1980).

Pada dasarnya secara inheren setiap verba memiliki derajat ketransitifannya masingmasing. Namun sebagaimana kita ketahui, verba merupakan unsur sentral sebuah klausa/kalimat dan kehadiran unsur-unsur klausa/kalimat lainnya sangat ditentukan oleh bentuk verba itu sendiri sebagai predikat. Bahkan, hadir tidaknya sebuah verba menentukan jenis kalimat verbal dan nonverbal (Sobarna, 2002). Sekalipun bahasa Indonesia dan bahasa Sunda serumpun serta memiliki tipologi yang sama-sama SVO (Gotama, $2001 \mathrm{hlm}$. 27), dalam hal derajat ketransitifan verbanya memiliki kekhasan masing-masing. Hal inilah yang menjadi kajian menarik dari penelitian ini untuk mengisi kekosongan penelitian-penelitian yang sudah dilakukan. 


\section{LANDASAN TEORI}

Konsep yang dapat dijadikan pegangan dari transitivitas dan voice antara bahasa Indonesia dan bahasa Sunda itu di antaranya sebagai berikut.

1. Batasan verba bahasa Sunda sangat berbeda dengan batasan yang dimiliki bahasa Indonesia, yakni perbedaan "objek" dan "pelengkap yang bermakna perpindahan"” yang didasari pada transitivitas.

2. Struktur kalimat bahasa Sunda pola "pelengkap bermakna perpindahan + verba intransitif" memiliki kandungan transitivitas tinggi dan rendah, sedangkan padanan dalam kalimat bahasa Indonesia transitivitas yang tinggi ini berpola "objek bermakna perpindahan+ verba transitif", dan transitivitas rendah ada pada pola "pelengkap bermakna perpindahan'+ verba intransitif'. Sebagai contoh perhatikan kalimat di bawah ini.

(a) Burung terbang di langit/ "Manuk hiber di langit."

(b) 1 Banyak mobil melewati jalan tol/ "Loba mobil ngaliwatan jalan tol."

2 Jalan tol dilewati oleh banyak mobil/"Jalan tol diliwatan ku loba mobil."

(Majalah Bobo)

Pada kalimat (a) "di langit" berperan sebagai pelengkap perpindahan, tetapi pada (b)1 "melewati jalan tol" berperan sebagai "objek bermakna 'kepindahan'. "Jalan tol" ini menjadi wajib kehadirannya bersamaan dengan verba perpindahan "melewati". Kalimat aktif dalam bahasa Indonesia dengan sendirinya dapat menjadi kalimat pasif apabila kalimat itu berupa ekatransitif yaitu kalimat bersubjek, berobjek tidak berpelengkap; dwitransitif, yaitu kalimat yang memiliki subjek, objek, dan pelengkap. Contoh (b)2 bentuk pasif dalam bahasa Sunda verba harus mengikuti objek (jamak) sehingga verba 'liwat' perlu digabungkan dengan prefiks $\boldsymbol{d i}$-+ penanda jamak bahasa Sunda infiks - ar- atau -al- + afiks -an.

Berdasarkan fenomena kebahasaan tersebut, peneliti tertarik untuk mengkaji tingkat ketransitifan baik verba bahasa Indonesia maupun bahasa Sunda. Hal ini diyakini bahwa dalam bahasa Indonesia dan bahasa Sunda terdapat komponen-komponen yang berkaitan erat dengan kekuatan verba dalam mengikat argumen inti pada sebuah kalimat. Hal ini akan tergambarkan dalam middle construction yang didasari teori Hopper \& Thompson berdasarkan hasil analisis yang dilakukan. Berdasarkan fenomena kebahasaan tersebut, tingkat ketransitifan baik verba bahasa Indonesia maupun bahasa Sunda menarik untuk dikaji. Secara universal, terdapat komponen-komponen yang berkaitan erat dengan kekuatan verba dalam mengikat argumen inti pada sebuah klausa/kalimat. Demikian pula halnya dengan verba bahasa Indonesia dan bahasa Sunda yang tergambarkan melalui paradigma middle construction sebagaimana dinyatakan oleh Hopper \& Thompson (1980).

\section{METODE PENELITIAN}

Penelitian ini menggunakan metode penelitian kualitatif. Metode yang digunakan untuk memahami makna dari fenomena, dengan mengkonstruksi hipotesis berdasarkan data yang didapat yang bersifat fakta dan alamiah (Sugiyono, 2020). Data dikumpulkan dengan menjelajah penggunaan kalimat yang dimuat pada media cetak (studi pustaka), dengan memanfaatkan media cetak yang telah dianggap mewakili penggunaan bahasa Sunda dan bahasa Indonesia karena mudah didapatkan oleh pembaca, yaitu data bahasa Sunda dari majalah Mangle (edisi 2018-2019), dan naskah drama bahasa Sunda "Lalakon" (terjemahan karya Fier Hilari, terdapat di dalam Mangle), sedangkan data bahasa Indonesia dari majalah Bobo (2019), koran Pikiran Rakyat (2019), serta buku acuan "Kajian Bentuk dan Makna Konseptual Preposisi Bahasa Sunda".

Sejumlah 89 data kalimat pasif terkumpul yang selanjutnya diklasifikasikan dan direduksi berdasarkan makna yang didukung oleh imbuhannya masing-masing yang melekatnya, dengan 
menjadikan penelitian terdahulu sebagai referensi. Sehingga data yang disajikan pada pembahasan hanya data yang dianggap mewakili penggunaan makna dari setiap kategori. Analisis pembahasan menggunakan pendekatan kontrastif antara bahasa Sunda dan bahasa Indonesia.

\section{PEMBAHASAN}

Penelitian ini memfokuskan pembahasan konstruksi tengah pada bahasa Indonesia dan bahasa Sunda. Berikut merupakan ciri khas struktur middle contruction berdasarkan skala transitivitas (Hopper \& Thompson, 1980).

Hubungan persesuaian dengan kalimat transitif, subjek pada struktur kalimat middle menyesuaikan dengan objek kalimat transitif yang mana subjek berperan bukan sebagai pengalam. Adanya pelaku yang potensial pada kalimat middle keberadaannya sangat bermakna. Bila pelaku merupakan orang yang tidak khusus sebagai pelaku perbuatan tidak akan muncul dalam kalimat middle. Selain itu pula yang berkaitan dengan waktu, bahwa pembatasan yang berkaitan dengan waktu pada kalimat middle tidak dapat menunjukkan waktu kejadian khusus. Kalimat middle ini pun memiliki makna modalitas yang lebih menunjukkan makna 'dapat/kewajiban', jadi secara prototipe lebih menekankan modalitas potensial. Satu hal lagi yang perlu dicermati adanya unsur adverbia yang menyertai pada kalimat middle ini. Perhatikan contoh Bahasa Indonesia yang berkaitan dengan kalimat middle tersebut.

a. Suara wanita itu terdengar. (= dapat didengar)

b. Kemarin Adi terpesona pada kecantikan wanita itu.(waktu lampau)

b'. ${ }^{*}$ Besok Adi terpesona pada kecantikan wanita itu. (*:tidak berterima)

c. Buku itu banyak terjual. (adverbia 'banyak' menyertai verba (ter-)

\section{Makna Pasif dalam Bahasa Indonesia (ter-), dan Padanannya dalam Bahasa Sunda}

Seperti yang telah dipaparkan sebelumnya, penelitian ini memfokuskan pembahasan transitivitas pada middle construction (konstruksi tengah), hal ini yang merupakan pembahasan yang belum dilakukan pada penelitian yang sudah ada. Berikut ini merupakan pembahasan hubungan prefiks dan makna pasif yang termasuk kedalam konstruksi tengah tersebut.

a. Ungkapan pasif secara spontan

(4) Adi terpesona pada kecantikan wanita itu.

'Adi kapincut ku kageulisan eta wanoja.'

(5) Pada waktu sendirian, pengalaman masa kecil kembali teringat.

'Lamun keur cicing sorangan, sok kaingetan pangalaman keur leutik.'

(Koran Pikiran Rakyat)

(Koran Pikiran Rakyat)

Prefiks (ter-) pada kalimat (4) dan (5) menunjukkan tidak ada kesengajaan maupun maksud dari pelaku. Akan lebih dapat dipahami apabila dibandingkan dengan bentuk aktif memesona dan mengingat yang jelas terlihat peranan pelaku. Selain itu baik terpesona (4) maupun teringat (5) berlangsung secara spontan, tidak membutuhkan waktu lama.

b. Ungkapan bentuk dapat-pasif

(6) Kemarin saya tertidur di dalam kereta api yang menuju ke Bandung. 'Kamari kuring kasarean dina kareta api anu ka arah Bandung-keun.'

(7) Pagi-pagi saya terbangun_karena ribut di luar kamar saya.

(Koran Pikiran Rakyat) 'Isuk-isuk kuring kahudangkeun lantaran ribut di luar kamar kuring.'

(Majalah Bobo) 
c. Ungkapan pasif yang tidak disadari

(8) Gereja besar itu terbakar karena tersambar petir.

'Gareja gede itu kahuruan ku sabab kasamber kilat.'

(9) Saya terjatuh karena lantainya licin. 'Kuring labuh lantaran lantena leueur.'

(10) Buku saya terbawa oleh Ida. 'Buku kuring kabawa ku Ida.'

(Koran Pikiran Rakyat)

(Majalah Bobo)

Prefiks (ter-) yang mendukung makna 'tidak disadari' dapat dipahami dari contoh kalimat (8) terbakar, (9)terjatuh , (10) terbawa di atas. Makna yang mengungkapkan aktivitas yang disadari maupun disengaja oleh pelaku akan menggunakan prefiks (di-) dalam bahasa Indonesia (Sobarna, C. dan Santy, 2019). Sehingga akan menjadi dibakar (8'), dijatuhkan (9'), dibawa (10'). Dalam hal ini terlihat perbedaan parameter derajat ketransitivitasan dalam hal kesadaran pelaku dalam melakukan aktivitas.

\section{Makna pasif dalam bahasa Sunda dan padanannya dalam bahasa Indonesia}

a. Prefiks ka- Menunjukkan Ketidaksengajaan, dan Menunjukkan bahwa Situasinya Telah Selesai

Djadjasudarma (1994) memaparkan bahwa terdapat verba yang hanya dapat bergabung dengan prefiks $\boldsymbol{k} \boldsymbol{a}$ - verba yang dapat bergabung dengan prefiks $\boldsymbol{k} \boldsymbol{a}$-, namun harus ditambahkan sufiks - an. ka- + -an biasanya bermakna bahwa sesuatu terjadi secara tidak diharapkan dan tak menguntungkan. Serta bentuk verba yang dapat bergabung baik dengan prefiks ka-, maupun simulfiks $\boldsymbol{k a}$ - -an, yang akan bermakna frekuentif (contoh: katajong-katajongan).

Verba pasif bermarkah $\boldsymbol{k} \boldsymbol{a}$ - dan $\boldsymbol{t i}$ - dalam bahasa Sunda sama persis dengan pemarkah $\boldsymbol{k e}$ dan ter- dalam bahasa Indonesia. Hanya saja dalam bahasa Sunda tipe kalimat pasif jenis ini dapat disisipi infiks - $\boldsymbol{a r}$ - atau -al-(Darheni, 2010). Selain itu, tipe kalimat pasif lain yang dapat diubah-ubah letaknya adalah tipe kalimat pasif yang predikatnya berafiks $\boldsymbol{k a} \boldsymbol{a}$-, sedangkan pasif berafiks ti- tidak dapat diubah-ubah letaknya (Darheni, 2010). Perhatikan contoh berikut.

(12) Tok-tok, tok-tok! ti luar kadenge sora tukang baso.

'Tok-tok, tok-tok! dari luar terdengar suara tukang baso'

(37) Kapaksa jadi tukang baso tahu heula

'Terpaksa menjadi tukang baso'

(Lalakon)

(Lalakon)

(57) Salila ieu Maria ngarasa kaganggu. 'Selama ini Maria merasa terganggu.'

(Lalakon)

(49) Kade siah sirah raja katajong!

'Awas kepala raja tertendang!'

(Lalakon)

(68) Dina kahirupan urang Sunda remen_kabejakeun "sok mangga ti payun" 'Dalam kehidupan orang Sunda, banyak tersiar kabar"sok mangga tipayun"

Kalimat (12) kadenge, (37) kapaksa, (57) kaganggu menunjukkan makna tidak disengaja dengan adanya dukungan prefiks ( $\boldsymbol{k a}$-), dan (49) bermakna pasif selesai. Apabila pelaku secara sengaja melakukan aktivitas tersebut maka akan menjadi (12') ngadenge, (37') maksa, (57') ngaganggu, (49') najong), (68') ngabejakeun. Dalam bahasa Sunda, verba bermakna aktif akan mengalami proses nasalisasi. 
b. Prefiks ka- makna potensial

(30) Ari di lembur loba keneh kabeuli beas?

'Apakah di kampung banyak yang dapat membeli beras?'

(Lalakon)

(1) Nu gering sarua teu kaubaran.

'Yang sakit sama tidak terobati'.

(Lalakon)

Verba kabeuli (30) menunjukkan makna potensial pada Bahasa Sunda. kabeuli dipadankan menjadi dapat membeli, karena dalam Bahasa Indonesia tidak ada padanan yang tepat yang dapat menggantikan prefiks yang bermakna dapat dalam konteks ini. Pada pembahasan sebelumnya, prefiks (ter-) merupakan prefiks yang dapat memberikan makna potensial, namun pada konteks kalimat (30) jika kabeuli diterjemahkan menjadi 'terbeli' hal ini akan memunculkan ambiguitas, bermakna 'tidak sengaja membeli', dan makna ini lebih kuat dibandingkan dengan makna 'dapat membeli'.

Berbedahalnya dengan kalimat (1) kaubaran, dapat dipadankan dalam Bahasa Indonesia menggunakan imbuhan ter- dan -i 'terobati'. Hal ini sesuai dengan makna (ter-) pada pembahasan sebelumnya. Pada konteks ini memrlukan akhiran -i karena kata dasar obat merupakan nomina, sehingga perlu penyempurnaan makna dengan menambahkan akhiran. Berbeda pada contoh 'terbaca' yang artinya 'dapat membaca/dapat dibaca', karena kata dasar'baca' merupakan verba dasar.

c. Prefiks ka- makna jamak

(31) Ari minyakna kabareuli keneh, Mang?

'Apakah minyaknya masih dapat terbeli?' (*

'Apakah masih banyak yang dapat membeli minyak?' (**

(Lalakon)

(52) Tendeun di tempat anu mindeng kaliliwatan jelema.

'Taruh di tempat yang sering terlewati*/dilewati orang'

(Mangle)

Kalimat (31) dan (52) bermakna jamak karena terdapat reduplikasi dwipurna (Djadjasudarma, 1994). Pada kalimat (31) terjadi morfosintaksis seperti di bawah ini:

beuli $>$ kabeuli $>$ kabareuli (sisipan - ar)

$\mathrm{kd}>\mathrm{ka}+\mathrm{kd}>\mathrm{ka}+$ infiks $-\mathrm{ar}-+\mathrm{kd}$

Pada kalimat (52) proses yang terjadi adalah:

liwat $>$ kaliwat $>$ kaliwatan $>$ kaliliwatan

$\mathrm{kd}>\mathrm{ka}+\mathrm{kd}>\mathrm{ka}+\mathrm{kd}+\mathrm{an}>\mathrm{ka}+\mathrm{li}+\mathrm{kd}+\mathrm{an}$

Verba dasar liwat, pada kalimat (52) dapat mengalami turunan seperti berikut; kaliwat 'terlewat', kaliwatan 'sering terlewati', kaliliwatan 'sering terlewati oleh banyak orang'. Reduplikasi dwipurna merupakan salah satu ciri khas yang dimiliki oleh bahasa Sunda. Proses ini tidak berterima jika dalam bahasa Indonesia, sehingga dalam menerjemahkan didak dapat dipadankan langsung ke dalam prefiks bahasa Indonesia.

(*:Lebih menjelaskan tentang objek,tetapi merupakan kalimat yang tidak berterima

(**: Lebih menekankan pada pelaku yang mampu melakukan hal tersebut dan ini merupakan kalimat yang berterima. 
d. Prefiksasi ting- + infiks -ar Mendukung Makna bahwa Suatu Situasi Terjadi secara Kebetulan/Tidak Sengaja

Coolsma (dalam Djadjasudarma, 1994) mengelompokkan verba bentuk ini ke dalam verba aktif karena subjeknya berperan sebagai agentif. Namun, tindakan itu bukan kemauan sendiri, melainkan tanpa disengaja.

(72) Sore tingkoceak mimiti ngurangan

Verba tingkoceak = prefiks ting + verba koceak (3 silabel)

(74) Ukur sarah patulayah jeung layon nu tingjarepat.

Verba tinjarepat $=$ prefiks ting + infiks ar + verba jepat $(3$ silabel)

(Mangle)

Sareretan katempo mangratus raga tingarangkleung ngarambang.

Verba tingarangkleung $=$ prefiks ting + infis - ar - + verba angkleung (2 silabel)

(Mangle)

(Mangle)

Prefiks ting- hanya dapat bergabung dengan verba bentuk dasar yang tiga silabel atau lebih. Verba yang bersilabel dua, akan mengalami infiksasi -ar- (-al-) (Djadjasudarma, 1994). Sehingga tidak semua verba dapat mengalami infiksasi seperti contoh. Makna yang didukung oleh prefix (ting-) adalah berarti 'saling'. Sedangkan prefiks dalam Bahasa Indonesia tidak ada yang sepadan yang bermakna 'saling'.

\section{Konstruksi tengah pada bahasa Indonesia dan bahasa Sunda}

Berdasarkan pemaparan contoh kalimat dan pengategorian di atas, dapat dikatakan bahwa kalimat middle memiliki kecenderungan adanya keterkaitan antara struktur kalimat bahasa Indonesia dan struktur kalimat bahasa Sunda yang memiliki 'verba berprefiks ter-'. Dengan melihat adanya keterkaitan keberadaan pelaku dan aktivitas yang tidak disadari, konstruksi tengah kalimat bahasa Indonesia berada di antara bentuk 'melakukan' (disadari) dan bentuk 'menjadi' (tidak disadari).

Grafik 1 berikut menunjukkan hubungan kalimat middle bahasa Indonesia dengan bahasa Sunda yang diidentifikasi berdasarkan baik pada keberadaan pelaku atas aktivitas atau perbuatan, maupun kejadian yang berlangsung.

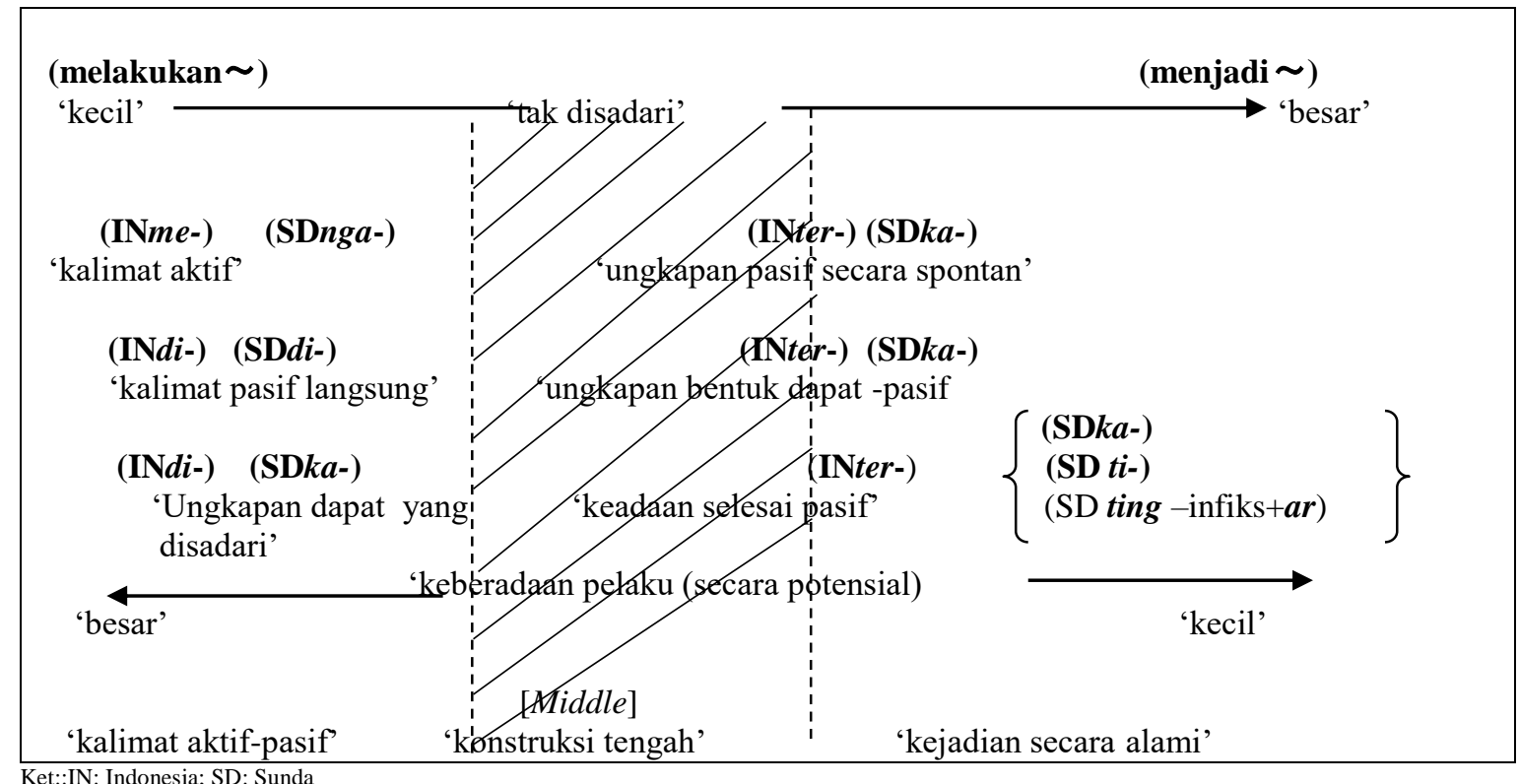

Grafik 1. Hasil analisis hubungan middle construction bahasa Indonesia dan ungkapan pasif spontanitas bahasa Sunda 
Baik bahasa Indonesia maupun bahasa Sunda memiliki prefiks khusus penanda aktif-pasif. Penelitian ini berfokus pada prefiks yang dapat memunculkan derajat ketrasitifitasan tinggi, yaitu -ter dalam bahasa Indonesia, dikontraskan dengan prefiks dalam bahasa Sunda (ka-, $\boldsymbol{t i}$-), keduanya memiliki makna yang sama, yaitu mendukung makna tidak disengaja. Namun ketika dikaji dengan contoh kalimat, tidak semerta-merta bahwa verba berprefiks ter- otomatis menjadi verba berprefiks $\boldsymbol{k} \boldsymbol{a}$ - ketika dipadankan dalam bahasa Sunda, begitupun sebaliknya. Prefiks -ter dalam bahasa Indonesia dapat menjadi $\boldsymbol{k a}-, \boldsymbol{k a}-\mathbf{+}-\boldsymbol{a n}, \boldsymbol{k a}-\mathbf{+} \boldsymbol{k e u n}$, serta dapat pula menjadi infiks +-in-, maupun verba dasar (nasal) dalam bahasa Sunda. Namun, prefiks $k \boldsymbol{a}$ dalam bahasa Sunda dapat menjadi -ter maupun $\boldsymbol{k e}$ - dalam bahasa Indonesia sebagai penguatan pada penelitian terdahulu (Djajasudarma, 1994; Darheni, 2010),dapat pula menjadi verba dasar disertai keterangan jamak.

\section{PENUTUP}

Baik bahasa Indonesia maupun bahasa Sunda memiliki prefiks khusus penanda aktif-pasif. Penelitian ini berfokus pada prefiks yang dapat memunculkan derajat ketrasitifitasan tinggi, yaitu -ter dalam bahasa Indonesia, dikontraskan dengan prefiks dalam bahasa Sunda (ka-, ti-), keduanya memiliki makna yang sama, yaitu mendukung makna tidak disengaja. Namun ketika dikaji dengan contoh kalimat, tidak semerta-merta bahwa verba berprefiks ter- otomatis menjadi verba berprefiks $\boldsymbol{k} \boldsymbol{a}$ - ketika dipadankan dalam bahasa Sunda, begitupun sebaliknya.

Prefiks - ter dalam bahasa Indonesia, dapat menjadi $k a-, k a-+-a n, k a-+k e u n$, serta dapat pula menjadi infiks +-in-, maupun verba dasar (nasal) dalam bahasa Sunda. Namun prefiks kadalam bahasa Sunda, dapat menjadi -ter maupun $\boldsymbol{k e}$ - dalam bahasa Indonesia sebagai penguatan pada penelitian terdahulu (Djadjasudarma, 1994), (Darheni, 2010), yaitu dapat pula menjadi verba dasar disertai keterangan jamak.

Dengan melihat makna yang diungkapkan dan didukung adanya prefiks, terjadi pergeseran derajat parameter ketransitivitasan. Hal ini yang menjadi poin penting keberadaan konstruksi tengah. Parameter dilihat dengan adanya keterlibatan pelaku dalam melakukan perbuatan; tinggi jika peranan kecil, rendah jika peranan besar; tinggi jika tidak disadari, rendah jika disadari. Prefiks (ter-) yang bermakna 'ungkapan bentuk dapat-pasif , (ter-) 'keadaan selesai pasif', dan (ter-) 'ungkapan pasif secara spontan' masuk kedalam kategori konstruksi tengah bahasa Indonesia.

Sedangkan dalam Bahasa Indonesia, tidak dapat dipisahkan antara prefiks dengan parameter ketransitivitasannya. Prefiks (ka-) dapat memiliki derajat rendah dalam makna 'potensial' karena adanya kesadaran pelaku, namun (ka-) dalam makna selesai pasif termasuk kedalam derajat parameter tengah.

\section{DAFTAR PUSTAKA}

Almatsier, A. M. (1994). How to master the Indonesian Language. Indonesia: Jambatan

Comrie, B. (1989). Language Universals and Linguistic Typology (Second Edi). The University of Chicago Press.

Darheni, N. (2010). Analisis Kontrastif Klausa Pasif Bahasa Indonesia Dan Bahasa Sunda : Tinjauan Morfosintaksis. Jurnal Sosioteknologi, 9(19), 844-855.

Djadjasudarma, F. T. (1994). Tata Bahasa Acuan Bahasa Sunda. Pusat Pembinaan dan Pengembangan Bahasa.

Djadjasudarma, F. T. (2006). Metode Linguistik. Refika Aditama.

Gurssel, M., K. Hale, M. Laughren, B. L. (1985). A cross linguistic study of transitivity alternations. Chicago Linguistic Society 2, 48-63.

Hopper, P. J., \& Thompson, S. A. (1980). Transitivity in Grammar and Discourse. Language, 56(2), 251-299. https://doi.org/10.2307/413757 
Iswara, P. D. (2010). Lalakon. https://sastradrama.wordpress.com/2010/10/13/prana-d-iswara-lalakonsunda/

Johanna Nichols, David A. Peterson, and J. B. (2004). Transitivizing and detransitivizing languages. 8(2), 149-211. https://doi.org/10.1515/lity.2004.005

Kadir, Puspa M. dan Pika Yestia Ginanjar. (2018). 500 Verba Bahasa Jepang. Unpad Press.

Kesuma, T. M. J. (2010). Verba Transitif dan Objek Dapat Lesap dalam Bahasa Indonesia. Masyarakat Linguistik Indonesia, 9(1), 46-60.

Muller-Gotama, Franz. (2001). Sundanese. Muenchen: Lincom.

Mulyadi, M. H. (2009). Kategori Dan Peran Semantis. Logat, V(1), 64.

Nishimura, Yoshiki (1993) Agentivity and causation in cognitive linguistics. In ; Kei-ichi Yamanaka \& Toshio Ohori (eds). The locus meaning: Papers in honor of Yoshiko Ikegami, 277-292. Tokyo: Kuroshio Publishers.

Paulino, F., Niron, M., \& Cendana, U. N. (2019). Tingkat Ketransitifan Verba Bahasa Lamaholot Dialek Ritaebang. 1-22.

Sembiring, S. I., \& Mulyadi, M. (2020). Verba Transitif dan Objek Dapat Lesap dalam Bahasa Karo (Transitive Verb and Deletable Object in Karo Language). Lensa: Kajian Kebahasaan, Kesusastraan, Dan Budaya, 9(1), 46. https://doi.org/10.26714/lensa.9.1.2019.46-60

Sobarna, Cece dkk. (2002). Verba Berkomplemen di dalam Bahasa Sunda. Jakarta: Pusat Bahasa.

Sobarna, C. dan Santy, Y. (2019). Kajian Bentuk dan Makna Konseptual Preposisi Bahasa Sunda. Refika Aditama.

Sugiyono. (2020). Metode Penelitian Kualitatif. Alfabeta.

Wojowasito, S. (1978). Pengantar Sintaksis Indonesia. Bandung: Sintha Dharma

Yuasa, Shouko. (2001). Nihongo, Indonesiago ni Okeru Tai to Tadousei 'Voice dan Verba Transitif pada Bahasa Jepang dan Bahasa Indonesia' (In Japanese). Kobe 